\title{
ACMT - conference on Advanced and Competitive Manufacturing Technologies in Moscow
}

\author{
Andrey Kutin ${ }^{1} \cdot$ Konrad Wegener ${ }^{2}$ \\ Published online: 23 August 2021 \\ (C) The Author(s), under exclusive licence to Springer-Verlag London Ltd., part of Springer Nature 2021
}

The conference of advanced and competitive manufacturing technology ACMT fulfills the desire to have a common platform among scientists and industries of western and eastern part of Europe. It was meant to build bridges between academia and industry and also between the two economical blocks, fighting with the same challenges in manufacturing. And it is a result of the long-term friendship between MSTU Stankin and the Institute of Machine Tools and Manufacturing of ETH Zürich, having now the 10th anniversary. It is recognized in full agreement that manufacturing as real value creation is the origin and basis of all wealth. Every thought of any engineer in the end leads to a product, and this product must be created in real materials. As this procedure must then be able to fulfill the quality requirements, tolerances, strength, reliability, and surface quality, manufacturing is not an easy task. And besides the product specs, also properties of the process as costs, exit rates, and production volume need to be realized. Manufacturing therefore needs thorough consideration concerning processes, manufacturing equipment, and factory organization. Manufacturing has changed drastically in the last decades and will be changing in the future. Huge trends like new mobility, digitization, biological transformation, sustainability, and climate change are rolling onto us and require suitable production measures. To make more out of less and to transform industries from a resource-based technology to a knowledge-based technology are the requirements to supply a growing

Konrad Wegener

wegener@iwf.mavt.ethz.ch

1 Moscow State University of Technology "STANKIN", Vice Rector for International Affairs, Vadkovskiy Pereulok, 1, Moscow 127055, Russia

2 Departement Maschinenbau und Verfahrenstechnik, Institut für Werkzeugmaschinen und Fertigung, ETH Zürich, LEE L214, Leonhardstrasse 21, CH-8092 Zürich, Switzerland population with an on average basis growing wealth. All those requirements are by far not yet solved and need to be pursued with eagerness. But of greatest importance in the future is the saving of material. A lot of effort is dedicated to energy efficiency and $\mathrm{CO} 2$ footprint, which solves immediate problems. But energy used is resupplied to the world by the largest power station nearly infinitely, by the sun. And also $\mathrm{CO} 2$ is cleaned out over time. But the earth is equipped with a certain amount of materials. Using this up leaves an exploited and exhausted planet. And manufacturing here plays a major role as being the active transformation in the generation of goods out of raw material and recycling the products in the end. Therefore the cooperation between Switzerland and Russia as representatives in really different kinds of economies can play a major role in the future. And this conference is dedicated to a better manufacturing world - benign to the humans and environment and competitive and efficient to create wealth.

This special issue contains the highlights of the conference.

The papers presented cover additive manufacturing, advanced cutting technologies, processing of materials and composites, and non-mechanical manufacturing technologies on the level of the manufacturing technologies. On the level of machine tool control and factory organization, the Industrie 4.0 and digitization aspects have found a significant place.

The conference had a keynote session with keynote lectures from Prof. Reimund Neugebauer, Konrad Wegener, Evgeny Bakhin, Ruslan Zvyagintsev, and Iskander Akhatov, which then are published in the Stankin journal. Prof. Neugebauer from his vast overview of technologies exposed the manufacturing technologies of tomorrow based on the essential trends visible in technology development and especially under development within Fraunhofer Society. Prof. Wegener showed a concept of future machine tools, 
which for the sake of autonomy and efficiency include functionalities which today the operator of the machine has to fulfill. A toolbox of AI technologies, sensory concept, and self-healing aspects has been covered. Mr. Bakhin presented aspects of digital transformation of Russian industries, and Mr. Zvyagintsev pointed onto the needs of Russian machine tool manufacturers. Mr. Akhatov demonstrated under the topic of multiscale materials and technologies the competences of Skolkovo Institute of Science and Technology.
At the end the organizers greatly acknowledge the great support from Prof. Elena Kataeva in setting up this conference, before she passed away due to COVID-19 in January 2021.

Publisher's note Springer Nature remains neutral with regard to jurisdictional claims in published maps and institutional affiliations. 